\title{
APOSTA NO SACRIFÍCIO E NO LADO IMPLACÁVEL DO Outro
}

\author{
Marta Gerez Ambertin* \\ Tradução: Ana Rudge**
}

\section{RESUMO}

O trabalho aborda a questão do sacrifício a partir das mudanças produzidas pela introdução do objeto $a$ na teoria de Lacan, analisando-o mais além da aliança e do intercâmbio, ressaltando sua vertente de gozo mortífero. Assim, o sacrifício é uma forma de legitimar plenamente o Outro, outorgando-lhe uma consistência que ele não tem. Desde então, discute-se a colaboração humana nos variados holocaustos dos séculos XX e XXI.

Palavras-chave: sacrifício, suplício, holocaustos, gozo

\section{Abstract}

THE BET IN SACRIFICE AND THE IMPLACABLE SIDE OF THE OTHER

The present paper accounts for sacrifice from the point of view of the changes caused by the introduction of the object " $a$ " in Lacan's theory. Sacrifice is then analyzed as being beyond alliance and exchange in order to highlight its deadly enjoyment. Thus, sacrifice is an attempt to thoroughly legitimate the Other, endowing him with the consistency he lacks. Human collaboration in the varied holocausts of the XX and XXI centuries is discussed under such a view.

Keywords: sacrifice, anxiety, holocausts, enjoyment

* Diretora do curso de Doutorado em Psicologia da Facultad de Psicologia da Universidad Nacional de Tucumán (Argentina).

** Psicanalista e Professora associada do Departamento de Psicologia da PUC-Rio. 
Ainda que a questão do sacrifício compareça na obra de Lacan desde 1938, a introdução do objeto a provoca uma virada em sua teoria sobre o Pai, produzindo uma importante reformulação em sua concepção do sacrifício. Isso porque, se o sacrifício supõe uma aliança com o Outro, ele é, também, uma transferência da causalidade do sujeito a esse Outro. Nesse ponto, coloca-se algo que vai mais além da aliança: trata-se da submissão ao Pai como senhor cruel, seja porque o sujeito se oferece gozosamente ao mesmo, seja porque este, como algoz, toma impunemente em suas mãos o destino das vítimas, mesmo quando estas se recusam a tal tortura.

É importante destacar que, apesar de, geralmente, ocorrer uma cumplicidade entre sacrificador e sacrificado ou entre algoz e vítima, nem sempre esta cumplicidade se realiza. Os holocaustos das últimas guerras mostram que, mais além das intençôes do algoz, alguns sujeitos e alguns grupos têm podido exercer uma forte resistência contra a busca de aniquilação apelando para o desejo, mais além do gozo claudicante de submeter-se ao senhor cruel. Como dizia H. Arendt "alguns não amoleceram" (Arendt, 1962: 353).

Nos primeiros trabalhos de Lacan sobre o sacrifício, suas formulações sobre o pacto de aliança e reciprocidade que ligam ao Outro adquirem certa hegemonia; sem dúvida, seus avanços na questão da compulsão à repetição atravessada pelo real demonstram que, se o sacrifício possibilita ao sujeito escapar da angústia, quando se fica na fascinação do sacrifício, já não é possível aplacar a exigência do Outro que oprime - mais além de todo pacto e intercâmbio -, abrindo-se a via para a intrusão superegóica e, assim, para a possível reinstalação da angústia. A que se deve essa opressão do Outro? Sem dúvida a uma renúncia. O sujeito acaba cedendo, ao Outro, a causa de seu desejo para, então, transitar pela paixão pela ignorância, fazendo-se servo do "suposto" desejo obscuro do Outro, ao qual se vincula atrás de uma culpa melancólica.

Lacan reformula os desenvolvimentos freudianos e os próprios a partir de sua teorização sobre o Pai, os gozos e finalmente o objeto $a$, que é pré-anunciado desde 1959. Encontramos uma antecipação sobre ele no seminário VII. Ali o objeto a possui um antecedente que se chama das Ding, ligado ao gozo, disjunto do desejo e vinculado aos paradoxos do Nome do Pai. Lacan diz: "Todo exercício do gozo comporta algo que se inscreve no Livro da dívida e na Lei. E muito mais ainda, é preciso que algo nessa regulação seja, ou bem paradoxo, ou bem lugar de algum desregramento...” (Lacan, 1959-60: 214).

O gozo não está, pois, desvinculado da Lei, mas refere-se ao desarranjo da Lei. Lei que surge da inscrição dos significantes do Nome do Pai. Assim, então, o sacrifício, como uma das versôes do gozo do Pai (père-version), estaria indisso- 
luvelmente ligado aos Nomes-do-Pai (finalmente pluralizado em 1963) e seus paradoxos. Em suma, a conjunção da lei com o desejo só procede sobreposta à "suposição do gozo puro do pai como gozo primordial" (Lacan, 20/11/1963): Desejo. Lei/gozo.

Eis que o pai falha: falha em seu gozo ao ceder o Nome, mas também falha no Nome ao ceder ao gozo - falha como fracasso em julgar, e como falha enquanto culpa. Sua enunciação no seminário XI: "O Pai, o Nome-do-Pai, sustenta a estrutura do desejo com a da Lei - mas a herança do pai, que nos designa Kierkegaard, é seu pecado" (Lacan, 1964: 46).

Se a herança do pai é, entre outros legados, também a de uma mácula, uma maneira de encobri-la é pela via do sacrifício. Como disse antes: o sacrifício é uma intenção de restaurar o laço de intercâmbio, um anseio de restaurar o Outro e o Pai. É preciso encobrir toda falha do Outro com a finalidade de assegurar-se de sua existência. A partir disso, o sujeito pode supor que tem um lugar no desejo do Outro e que pode incitar sua proteção.

[...] esse instante paradoxal em que a criança descobre que seu pai é mau, mas quer, sem dúvida, continuar sendo seu filho. Só lhe resta uma saída diante desta contradição (e esta é a tragédia): que o filho carregue a falta do pai, que a culpa da criatura libere a divindade. O Pai oprime sem justiça: bastará merecer em retrospectiva seus golpes para que sejam justos. O sangue é exatamente o veículo desta retroação. Pode-se dizer que todo herói trágico nasce inocente: faz-se culpado por salvar a Deus (Barthes, 1963: 86).

É possível dizer que todo filho nasce inocente e faz-se culpado para salvar o Pai e limpar suas máculas. A doação sacrificial é a maneira de responder à culpa e ao anseio de salvar o pai, já que, por suas faltas, se desejou inconscientemente a sua morte. A erótica sacrificial ao Pai supõe que o pagamento pela falta sempre excede a dimensão da mesma: o castigo não é proporcional ao crime, sempre se paga mais.

O que está em jogo nessa oferta de um filho para salvar o pai? Por que todo filho estaria tentado a sucumbir à doação sacrificial? Por que, apesar disso, nem todos sucumbem? O que detém o gozo sacrificial de alguns? O que precipita os outros em direção a um bramir de gozo imolador? Para Lacan, trata-se de algo profundamente disfarçado na crítica da história que temos vivido. Trata-se, atualizando as formas mais monstruosas e pretensamente superadas do holocausto, do drama do nazismo.

Sustento que nenhum sentido de história, baseado nas premissas hegelianomarxistas, é capaz de dar conta desse ressurgimento, pois ele revela que a oferenda 
de um objeto de sacrifício aos Deuses obscuros é algo a que poucos sujeitos conseguem não sucumbir, em uma monstruosa captura.

A ignorância, a indiferença, o desvio do olhar podem explicar sob que véu se mantém escondido esse mistério. Mas, para quem quer que seja capaz de dirigir para esse fenômeno um olhar corajoso - e, uma vez mais, pouco há de seguro para não sucumbir à fascinação do sacrifício em si mesmo -, o sacrifício significa que, no objeto do nosso desejo, tentamos encontrar o testemunho da presença do desejo desse Outro que aqui chamamos de Deus obscuro (Lacan, 1964: 277-78).

O campo lacaniano lança um olhar corajoso para essa forma de gozo que é o sacrifício: o que leva os seres humanos à compulsão à repetição pelo holocausto? O que é essa horrorosa aposta na tortura sacrificial? É preciso cautela para responder a este enigma.

Fizemos referência, tanto em As vozes do supereu (Gerez Ambertín, 1993) como em Imperativos do supereu (Gerez Ambertín, 1999), a esta tentação sacrificial ligada ao impedimento de um luto pelo pai ideal. Deixar o pai imaculado parece ser a missão universal de todo filho. Mas convém ressaltar que, se desejamos salvar o pai, é para ter um manto protetor, uma coberta que livre cada sujeito da responsabilidade de implicar-se em seus desejos e gozos. Tremendo e auspicioso empreendimento este, o de confrontar-se com a própria orfandade e com a irremediável herança da inconsistência do pai!

A aposta pelo salvamento impossível do pai ideal precipita o gozo sacrificial. É só pela recusa em sustentar tal empreendimento - atravessando os labirintos do luto por esse pai - que uma outra aposta se faz possível: a economia do sacrifício que pode advir transitando pelos caminhos do desejo atado à castração.

Se o Outro não pode ser legitimado definitivamente, uma maneira de pretender elevá-lo à condição de garante pleno é oferecer-lhe uma libra de carne em uma dupla dimensão:

- como significante: "esse sacrifício de si mesmo, esta libra de carne empenhada em sua relação com o significante" (Lacan, 22/04/60) e

- como objeto $a$ :

Entre o sujeito, que aqui se encontra, por assim dizer, "Outrificado", se posso me expressar desse modo, em sua estrutura de ficção, e o Outro $\mathrm{A}$, não autenticável, nunca inteiramente autenticável, o que surge é esse resto, $a$, é a libra de carne. O que quer dizer que podemos fazer todos os empréstimos que quisermos para tampar os furos do desejo, assim como os da melancolia; mas lá está o judeu que, por sua vez, entende um bocado do balanço de contas e que, no fim, pede a libra de carne (Lacan, 2004: 139). 
Doação de um bem que é sacrificado pelo gozo, ponto no qual, como sublinha Lacan no Seminário da Ética, o desejo ali se perde atrás de um bem. Franco perfil de usufruto de um gozo que prima em tal concessão. Assim, o sacrifício persegue, em um só movimento, duas operaçōes: captar a falta do Outro, mas para encobri-la, para velar sua inconsistência, ou, extremando nossa posição, a inexistência do Outro (Lacan, 1959-1960/1984).

Daí que Lacan, em 1963, relaciona o sacrifício tanto com o desejo como com o gozo do Outro. Nesse sentido, o sacrifício tenta ser não só uma oferenda de reconciliação com o Outro, destinada a conquistar seu desejo (o que vincula o sacrifício com o amor), mas também uma maneira de alimentar seu gozo (o que vincula o sacrifício com o horror).

Do Seminário inconcluso de 1963, deduz-se uma posição estrutural da subjetividade com respeito ao sacrifício: todos podemos ser tentados pelo gozo ou pela fascinação do sacrifício. Mas, em 1964, Lacan afirmará que "alguns” podem recusar seu oferecimento, escapar desta monstruosa sedução. Para alguns, a aposta no desejo está acima do gozo.

Um exemplo é o caso, mencionado por H. Arendt, do sargento alemão Anton Schmidt, que

estava a mando de uma patrulha que operava na Polônia, dedicada a recolher soldados alemães que haviam perdido o contato com as suas unidades. No desenrolar desta atividade, Schmidt havia entrado em contato com membros das organizaçôes clandestinas judias [...] e havia ajudado guerrilheiros judeus, proporcionando-lhes documentos falsos e caminhōes do exército. E, o que é ainda mais importante: "Não o fazia para obter dinheiro". O anterior durou cinco meses, desde outubro de 1941 até março de 1942, quando Schmidt foi descoberto e executado (Arendt, 1962: 348-349).

Até nos casos de alguns que se rebelam contra o sacrifício, há a possibilidade de que o carrasco invada e ocupe suas vidas. Mas, como acrescenta Arendt,

A lição da história (do sargento Schmidt) é simples e está ao alcance de todos. De um ponto de vista político, nos diz que, em circunstâncias de terror, a maioria das pessoas fraqueja, mas alguns não fraquejarão. Do mesmo modo, a lição que nos dão os países aos quais se propôs a aplicação da Solução Final é que "pôde colocar-se em prática" na maioria deles, mas não em todos. De um ponto de vista humano, a lição é que atos como estes que comentamos constituem o que se necessita, e não se pode razoavelmente pedir mais, para que este planeta siga sendo um lugar apto para que o habitem seres humanos (Arendt, 1962: 352-353). 
Em suma, e como destacamos antes, em alguns a aposta no desejo pode estar acima do gozo, alguns podem recusar-se à monstruosa captura pelo sacrifício.

\section{REFERÊNCIAS BIBLIOGRÁFICAS}

Arendt, H. (1962). Eichmann en Jerusalén - un estudio sobre la banalidad del mal. Barcelona: Lumen, $2^{\mathrm{a}}$ ed., 1999.

Barthes, R. (1963). Sobre Racine. México: Siglo XXI, 1992.

Gerez Ambertín, M. (1993). Las voces del superyó. Buenos Aires: Manantial.

. (1999). Imperativos del superyó. Buenos Aires: Lugar Editorial.

. (2003). As vozes do supereu. Teresópolis: Editora De Cultura y Editora da Universidade de Caxias do Sul.

Lacan, J. (1958-59). El Seminario, Libro VI - El deseo e su interpretación. Inédito.

. (1959-1960). El Seminario, Libro VII - La ética del psicoanálisis. Buenos Aires:

Paidós, 1988.

. (1962-63). O Seminário, Livro X - A angústia. Rio de Janeiro: Zahar, 2005.

. (1964). El Seminario, Libro XI - Los cuatro conceptos fundamentales del

psicoanálisis. Barcelona: Barral, 1977.

Recebido em 20 de janeiro de 2006 Aceito para publicação em 5 de março de 2006 